\title{
Oral Health and Treatment Needs among 18-Year-Old Iranians
}

\author{
Hossein Hessaria, ${ }^{a}$ Miira M. Vehkalahtia ${ }^{\text {Mohammad J. Eghbal }}{ }^{\mathrm{b}}$ \\ Hamid Samadzadeh ${ }^{c}$ Heikki T. Murtomaa ${ }^{a}$

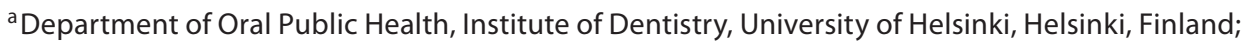 \\ ${ }^{b}$ Department of Community Oral Health, School of Dentistry, Shaheed Beheshti Medical University, and \\ 'Oral Health Bureau, Ministry of Health and Medical Education, Tehran, Iran
}

\section{Key Words}

Oral health · Adolescents · Iran · Caries - Periodontal

treatment needs

\begin{abstract}
Objective: To investigate the oral health status of 18-yearold Iranians in relation to their gender, place of residence and level of education. Subjects and Methods: Thirty-three calibrated examiners in 2002 collected data as part of a national survey, according to World Health Organization criteria for sampling and clinical diagnoses, across 28 provinces. The study sample was 4,448; male: 2,021 and female: 2,427 made up of urban: 2,564 and rural: 1,884 . Oral health status was assessed in terms of number of teeth, decayed teeth (DT), filled teeth (FT), decayed, missing or filled teeth (DMFT), community periodontal index and plaque index. Results: The mean number of teeth was 27.4, with DMFT: 4.3, DT: 3.0 and FT: 0.7. The mean number of sound teeth was higher $(p<0.01)$ in men (24.1 vs. 23.3 in women), FT in urban residents (1.0 vs. 0.2 in rural residents) and DT in women (3.3 vs. 2.8 in men). Three of 4 subjects were in need of restorative treatments. All subjects had dental plaque; $387(8 \%)$ healthy gingiva; 1,016 (23\%) exhibited bleeding; 2,025 (48\%) calculus and 1,020 (21\%) deepened pockets. Men's periodontal status
\end{abstract}

was worse than women's $(p<0.002)$. Low level of education was associated with having 27 or fewer teeth $(O R=1.7)$, calculus $(O R=1.5)$ or deep periodontal pockets $(O R=2.7)$. Conclusion: A majority of 18-year-old Iranians seem to enjoy a full dentition. High prevalence of dental plaque, calculus, periodontal pockets and untreated dental caries especially among underprivileged groups may put them at risk for tooth loss in adulthood.

Copyright $\odot 2008$ S. Karger AG, Basel

\section{Introduction}

Dental caries has been brought under control in children to a certain degree in industrialized countries [1-3]. However, the incidence of new carious lesions through adulthood has been evidenced, which varies considerably by socio-economic status $[3,4]$ in all countries, including those in the Eastern Mediterranean Region (EMR) $[5,6]$.

Adolescents comprise one fifth of the world's population [6]. Similarly, in the neighbouring EMR countries, one half of the population in Iran is below 25 years of age $[7,8]$. Information on child and adolescent oral health and related factors show that 12 -year-olds in most of the 
EMR countries have low to moderate levels of decayed, missing, or filled teeth (DMFT), but high occurrence of bleeding and calculus $[9,10]$. However, for the 18-year age group [11, 12], limited information exists [World Health Organization (WHO)] [13]. This is true also for the developed countries $[4,14,15]$, and none of the data sets in the EMR countries have a national perspective.

Oral health services, as an important aspect of general health, were integrated in the primary health care system in Iran in 1997. To date, free preventive oral health care is focused on target groups such as primary school children and pregnant women. Young adults, however, have no access to subsidized dental care [16].

The aim of the present survey was to assess the oral health and treatment needs among 18-year-old Iranians in relation to level of education and place of residence.

\section{Subjects and Methods}

The present data were collected during a national survey carried out in Iran in 2002 under the supervision of the Oral Health Department, the Ministry of Health and Medical Education and the Iran Centre for Dental Research [17].

The target population for the national survey included all Iranians aged 15-19 years living in Iran. Stratified cluster random sampling followed the WHO guidelines [18]. Within each of the 28 provinces and separately in the capital, Tehran (totalling 29 provinces), 15 clusters were defined. In each cluster, 23 people were invited, but no more than 20 were examined, totalling 300 subjects in each province and 8,700 for the whole country. Of the $8,700,4,448$ (2,021 males and 2,427 females) were between 17 and 19 years of age and were grouped together as 18 -year-olds. Of the $4,448,2,564$ were urban, 1,884 rural and 3,837 had at least a high school level of education.

The examiners received 4 days of training and calibration using a previously described method [17]. The final agreement for the 33 examiners, evaluated with $\kappa$ values for DMFT, decayed teeth (DT), filled teeth (FT), number of teeth and community periodontal index (CPI), ranged between 0.6 and 0.9 .

Prior to the clinical examination, the subjects provided information on their date of birth, gender, place of residence - urban or rural - and level of education. Educational level was grouped into low: illiterate and primary school; medium: secondary to high school and high: high school diploma and university education.

For the clinical examinations, the instruments, examination procedures and diagnostic criteria, the WHO recommendations were followed [18]. A flat mouth mirror, disclosing tablet and a WHO probe by Dentsply ${ }^{\mathrm{TM}}$ were used to examine the subjects under a dental light in the nearest public dental health centre. Dental status was diagnosed for all teeth except for third molars and periodontal and oral hygiene status for each sextant. The number of existing teeth, DT and FT were noted by the examiner and recorded by an assistant, separately for anterior and posterior teeth. CPI and visible dental plaque, as modified plaque index, were described according to the highest score of the measurements and as mean numbers of sextants with each index score [19].

Data were entered in Epi Info 6 [20] format with checkpoints and with double entry of $10 \%$ of the cases. The present estimates of oral health were adjusted for the proportions of 18 -year-olds in each province from among all 18-year-olds in the country [8]. Point estimates (means) are presented with $95 \%$ confidence interval (95\% CI). Differences between the subgroups were evaluated by $t$ test and ANOVA for mean values and by $\chi^{2}$ for frequencies. Logistic regression models were fitted to the data to evaluate the strength of the relationships between socio-demographic indicators and oral health indices. The corresponding results were expressed as odds ratios (OR) and their 95\% CI were calculated.

\section{Results}

\section{Dental Status}

The 18-year-old Iranians had an average of 27.4 teeth, of which 23.7 were sound (table 1). Of the 4,448, 3,071 (70\%) retained all their teeth, $703(16 \%)$ had lost 1 tooth, 383 (8\%) 2 teeth and 291 (6\%) 3 or more. Tooth loss was less prevalent among men ( 28 vs. $32 \%$ in women, $\mathrm{p}<$ 0.01 ), urban residents ( 29 vs. $33 \%$ in rural residents, $\mathrm{p}=$ 0.03 ) and those with a high level of education ( 27 vs. $40 \%$ in subjects with a low level of education, $\mathrm{p}<0.001)$.

Of the 4,448 subjects, 1,109 (26\%) did not have DT; 514 (12\%) had 1 DT in need of restoration, 652 (14\%) 2 and $2,173(48 \%) 3$ or more. Intact dentition $(\mathrm{DMFT}=0)$ was found in $772(18 \%)$ of the subjects, $942(22 \%)$ had $1-2$ DMFT, 1,308 (27\%) 3-5 and 1,426 (33\%) 6 or more DMFT. Subjects who had experienced tooth loss had more ( $\mathrm{p}<$ 0.001) decayed and filled teeth (4.5) compared to those who without tooth loss (3.4). For all subjects, the decay component dominated in the DMFT index (DT: 70\%; MT: $14 \%$; FT: 16\%).

Overall, 3,706 (81\%) did not have FT, 370 (10\%) had 1-2 and 372 (9\%) 3 or more. The mean number of FT was greater among urban than rural residents (table 1); 0.8 vs. 0.2 for men and 1.2 vs. 0.3 for women. Most of the DT (63\%) and FT (93\%) were posterior teeth. Of the 3,337 subjects in need of restoration, 2,801 (81\%) did not have FT, and the remaining 536 (19\%) had a mean number of FT of 3.1.

Having 1 or more DMFT was more likely among women $(\mathrm{OR}=1.5,95 \% \mathrm{CI}=1.3-1.6)$ and among those who were urban residents $(\mathrm{OR}=1.2,95 \% \mathrm{CI}=1.1-1.3)$. Having 28 teeth was more likely among men $(\mathrm{OR}=1.2,95 \% \mathrm{CI}=$ 1.1-1.2) and among those having a high level of education $(\mathrm{OR}=1.7,95 \% \mathrm{CI}=1.5-1.9)$. 
Table 1. Dental health indicators as means and 95\% CI (in parentheses) by gender, place of residence and level of education in 18 -yearold Iranians $(n=4,448)$

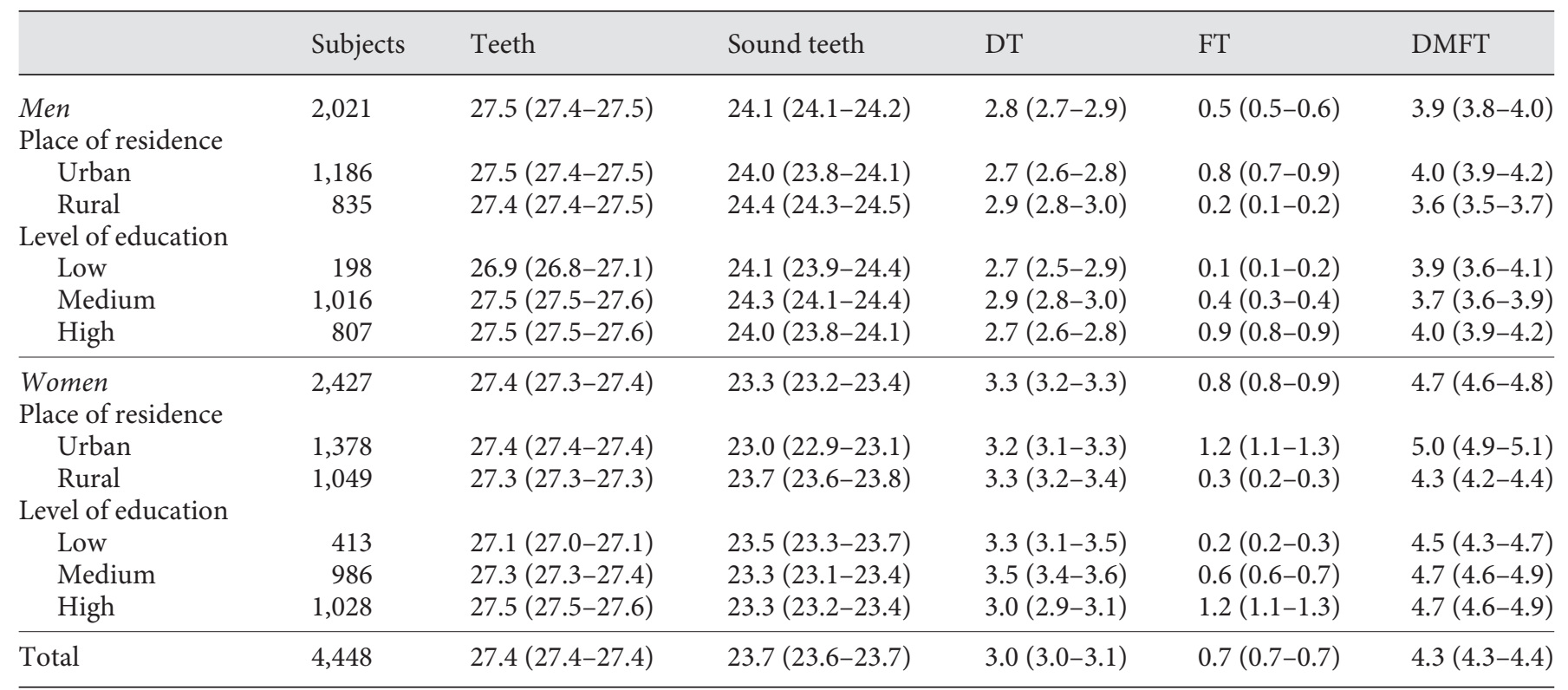

All estimates were adjusted to reflect the provincial proportions of the 18-year-old population.

Table 2. Distribution of 18 -year-old Iranians $(n=4,448)$ for maximum CPI findings by gender, place of residence and level of education

\begin{tabular}{|c|c|c|c|c|c|c|}
\hline & Subjects & Healthy & Bleeding & Calculus & Shallow pocket & Deep pocket \\
\hline Men & 2,021 & $168(8)$ & $429(21)$ & $926(47)$ & $480(23)$ & $18(1)$ \\
\hline \multicolumn{7}{|l|}{ Place of residence } \\
\hline Urban & 1,186 & $104(8)$ & $262(22)$ & $520(46)$ & $291(23)$ & $9(1)$ \\
\hline Rural & 835 & $64(7)$ & $167(20)$ & $406(50)$ & $189(22)$ & $9(1)$ \\
\hline \multicolumn{7}{|l|}{ Level of education } \\
\hline Low & 198 & $7(4)$ & $28(13)$ & $116(62)$ & $45(20)$ & $2(1)$ \\
\hline High & 807 & $76(9)$ & $177(23)$ & $361(46)$ & $186(21)$ & $7(1)$ \\
\hline Women & 2,427 & $219(8)$ & $587(24)$ & $1,099(48)$ & $493(18)$ & $29(2)$ \\
\hline \multicolumn{7}{|l|}{ Place of residence } \\
\hline Urban & 1,378 & $130(8)$ & $366(27)$ & $591(45)$ & $279(19)$ & $12(1)$ \\
\hline Rural & 1,049 & $89(7)$ & $221(19)$ & $508(53)$ & $214(19)$ & $17(2)$ \\
\hline Total & 4,448 & $387(8)$ & $1,016(23)$ & $2,025(48)$ & $973(20)$ & $47(1)$ \\
\hline
\end{tabular}

Statistical evaluation by $\chi^{2}$ test; $\mathrm{p}<0.05$ for all differences between the genders and separately for men and women according to place of residence and education. All estimates were adjusted to reflect the provincial proportions of the 18-year-old population. Figures in parentheses are percentages. 
Fig. 1. Mean numbers of all sextants for each CPI code, by gender, place of residence and level of education in 18-year-old Iranians $(\mathrm{n}=4,448)$.

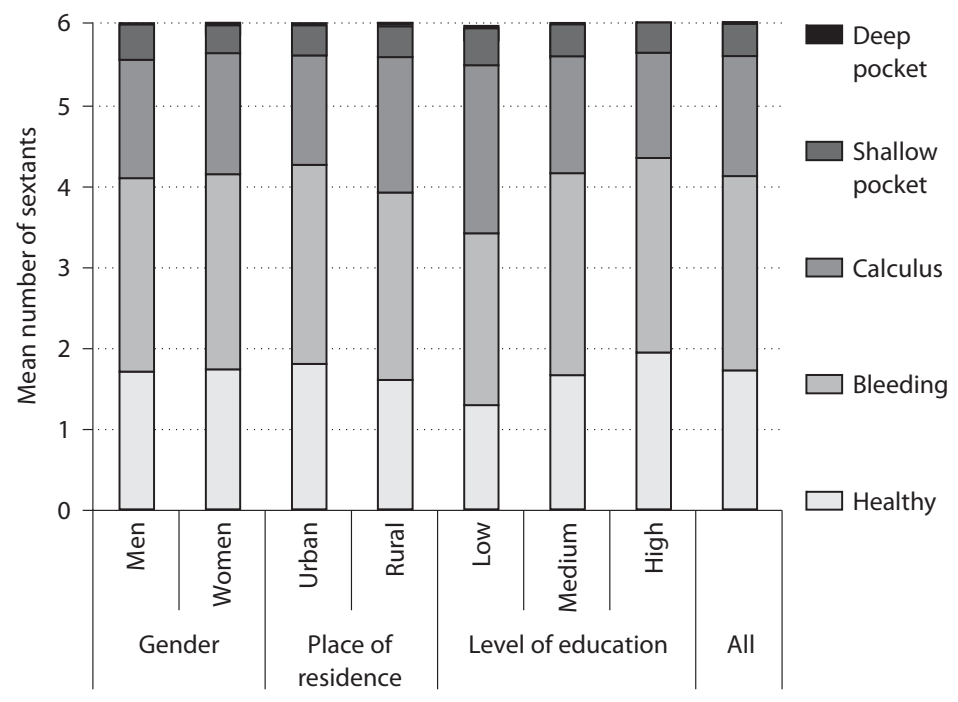

\section{Oral Hygiene and Periodontal Findings}

Visible plaque was found in nearly all subjects, and $3,528(81 \%)$ had at least 1 index tooth fully covered by plaque; the mean number of sextants with no dental plaque (plaque index $=0$ ) was 0.2 , and the mean number of sextants with at least 1 index tooth fully covered by plaque (plaque index $=3$ ) was 3.6.

Healthy periodontium was rare: $387(8 \%)$ had CPI $=0$ (table 2). This situation was most prevalent among those with a high level of education. Need for periodontal therapy was frequent; every second subject $(2,020)$ had CPI = 2 (48\%), and 1,020 (21\%) had deepened periodontal pockets.

The mean number of all sextants by CPI scores and subjects' socio-demographic information are shown in figure 1 . Those with a low level of education had the lowest mean number of healthy $(\mathrm{CPI}=0)$ sextants $(1.4)$.

Of the 4,448, 1,938 (44\%) 18-year-olds had no healthy sextant, 1,182 (26\%) had 1-2, and 1,328 (30\%) had at least 3 healthy sextants.

Calculus (CPI $=2$ ) was more common in anterior mandibular sextants (43\%) compared to all posterior sextants (23\%). Calculus was more likely among rural residents $(\mathrm{OR}=1.2,95 \% \mathrm{CI}=1.2-1.3)$ and subjects with a low level of education $(\mathrm{OR}=1.5,95 \% \mathrm{CI}=1.4-1.7)$. Having deep pockets $(\mathrm{CPI}=4)$ was more likely among those with a low level of education $(\mathrm{OR}=2.7,95 \% \mathrm{CI}=1.9-4.0)$.

\section{Discussion}

A study at national level has inherent difficulties [21] and limitations as explained previously [17]. However, completing this survey was facilitated by the widespread primary health care network that covered most of the urban and rural areas [22].

The lack of updated data on the oral health of 18-yearolds in the EMR makes comparison with neighbouring countries difficult. However, based on the existing WHO data bank [9], the mean DMFT values for 18-year-olds vary from 1.7 in Egypt and 3.3 in Bahrain to 11 for Iraq, all being dominated by DT. The figures for developed countries are somewhat similar in terms of DMFT index, but with dominant FT and fewer DT [9]. The DMFT index of 4.3 in the present study is higher than that for the corresponding age group in China [23] and in Burkina Faso [12].

The need of restorative treatments was common. Our findings confirm the positive relationship between FT, level of education and living in urban areas reported previously [4]. Skewed distribution of FT and DT in terms of place of residence indicates that access to dental services is not evenly distributed. Men had generally better dental health than women, similar to findings of lower DMFT indices for boys than girls [12, 23, 24], but inconsistent with the results from the UK [4]. 
The present estimate for Iranians retaining all their teeth at the age of $18(70 \%)$ is far from the goal of $85 \%$ recommended by the WHO and FDI [13]. Comparison of our findings with the suggested goal for 'acceptable' periodontal health based on at least 3 healthy sextants for $90 \%$ of the adults aged 18 [25] indicates that much remains to be done both individually and professionally. The frequency of healthy sextants was similar to that in existing data from other EMR countries [9].

Bleeding on probing is known as a probable risk marker for periodontal disease [26]. However, most gingival inflammations do not progress to periodontitis [27, 28]. Our findings confirm the rapidly changing pattern of oral diseases from chronic infectious model to new scope of a lifestyle disease with socio-environmental dimensions [5]. The high prevalence of dental plaque as a wellproven cause of dental and periodontal diseases $[28,29]$ necessitates extending preventive programs to adolescents in addition to those suggested for children [30].

The CPI has been applied in a number of studies [11, 28], since it is still recommended by the WHO [18] to increase the international uniformity of epidemiological studies on periodontology. However, some shortcomings for the CPI have been pointed out, such as the weak un- derlying hierarchical principle, partial recordings and distorted estimates of periodontal destruction in the population [31, 32].

Primary school children in Iran have used sodium fluoride mouth rinse weekly since 1997 . This might not have hindered the development of dental caries among the 18year-olds, since the present subjects were 12 years old in 1995 , when the mean number of DMFT was 2 [10]. About 6 years later, in 2002, the mean number of DMFT had increased to 4.3 , with an average annual increase of 0.4 . This trend seems to follow that found in Norway [14].

\section{Conclusion}

The high proportion of 18-year-olds retaining all permanent teeth indicates that the burden of oral diseases is still manageable. The high prevalence of dental plaque and calculus in 18-year-old Iranians requires a preventive population strategy with special emphasis on the improvement of oral hygiene. Higher treatment needs among underprivileged groups should be specially considered in any future oral health program.

\section{References}

1 Downer MC: Caries prevalence in the United Kingdom. Int Dent J 1994;44(suppl 1):365370.

2 Dye BA, Tan S, Smith V, Lewis BG, Barker LK, Thornton-Evans G: Trends in oral health status: United States, 1988-1994 and 1999_ 2004. National Center for Health Statistics. Vital Health Stat 11 2007;248:1-92.

3 Petersen PE, Bourgeois D, Ogawa H, Estupinan-Day S, Ndiaye C: The global burden of oral diseases and risks to oral health. Bull World Health Organ 2005;83:661-669.

4 Kelly M, Steele J, Nuttall N, Bradnock G, Morris J, Nunn J, Pine C, Pitts N, Treasure E, White D: Adult Dental Health Survey. Oral Health in the United Kingdom 1998. London, Her Majesty's Stationery Office, 2000.

5 Petersen PE: Socio-behavioural risk factors in dental caries - international perspectives. Community Dent Oral Epidemiol 2005;33: 274-279.

-6 Petersen PE: The World Oral Health Report 2003: continuous improvement of oral health in the 21st century - the approach of the WHO Global Oral Health Program. Community Dent Oral Epidemiol 2003;31(suppl 1):3-24.

7 Internet World Stats. 2005. http://www.internetworldstats.com/middle.htm (accessed 2006).
8 Statistical Centre of Iran: Iran Statistical Yearbook 2002. Tehran: Statistical Centre of Iran, 2002.

9 WHO Oral Health Country/Area Profile. Geneva, World Health Organization, 2005. http://www.whocollab.od.mah.se/index. html/ (accessed 2006).

10 Samadzadeh H, Hessari H: Oral Health Situation of Iranian Children 1997. Tehran, Ministry of Health and Medical Education, Under-Secretary of Health, Oral Health Bureau, 1999.

11 Corbet EF, Zee KY, Lo EC: Periodontal diseases in Asia and Oceania. Periodontol 2000 2002;29:122-152.

12 Varenne B, Petersen PE, Ouattara S: Oral health status of children and adults in urban and rural areas of Burkina Faso, Africa. Int Dent J 2004;54:83-89.

13 Aggeryd T: Goals for oral health in the year 2000: cooperation between WHO, FDI and the national dental associations. Int Dent J 1983;33:55-59.

14 Birkeland JM, Haugejorden O, von der Fehr FR: Analyses of the caries decline and incidence among Norwegian adolescents 19852000. Acta Odontol Scand 2002;60:281-289.
15 US Department of Health and Human Services: Oral Health in America. A Report of the Surgeon General. Rockville, US Department of Health and Human Services, National Institute of Health, National Institute of Dental and Craniofacial Research, 2000. NIH Publication No 00-4713. http://www. surgeongeneral.gov/library/oralhealth/ (accessed 2006)

16 Pakshir HR: Oral health in Iran. Int Dent J 2004;54(suppl 1):367-372.

17 Hessari H, Vehkalahti MM, Eghbal MJ, Murtomaa HT: Oral health among 35- to 44year-old Iranians. Med Princ Pract 2007;16: 280-285.

18 World Health Organization: Oral Health Surveys. Basic Methods, ed 4. Geneva, World Health Organization, 1997.

19 Silness J, Löe H: Periodontal disease in pregnancy. II. Correlation between oral hygiene and periodontal condition. Acta Odontol Scand 1964;22:121-135.

20 Center for Disease Control and Prevention: Epi Info ${ }^{\mathrm{TM}}$ 6. 2005. http://www.cdc.gov/ EPIINFO/Epi6/ei6.htm (accessed 2006).

-21 Schwarz E, Zhang HG, Wang ZJ, Lin HC, Lo EC, Corbet EF, Wong MC: An oral health survey in southern China, 1997: background and methodology. J Dent Res 2001;80:14531458. 
-22 Asadi-Lari M, Sayyari AA, Akbari ME, Gray D: Public health improvement in Iran - lessons from the last 20 years. Public Health 2004;118:395-402.

-23 Wang HY, Petersen PE, Bian JY, Zhang BX: The second national survey of oral health status of children and adults in China. Int Dent J 2002;52:283-290.

-24 Raitio M, Pienihäkkinen K, Scheinin A: Multifactorial modelling for prediction of caries increment in adolescents. Acta Odontol Scand 1996;54:118-121.
5 Ainamo J, Tervonen T, Nordblad A, Kallio P: Use of CPITN cross-tabulations - a research perspective. Int Dent J 1987;37:173-178.

26 Page RC, Beck JD: Risk assessment for periodontal diseases. Int Dent J 1997;47:61-87.

27 Albandar JM: Global risk factors and risk indicators for periodontal diseases. Periodontol 2000 2002;29:177-206.

28 Sheiham A, Netuveli GS: Periodontal diseases in Europe. Periodontol 2000 2002;29:104121.

29 Selwitz RH, Ismail AI, Pitts NB: Dental caries. Lancet 2007;369:51-59.
30 Mautsch W, Sheiham A: Promoting Oral Health in Deprived Communities. Berlin, German Foundation for International Development, 1995.

31 Pilot T, Barmes DE: An update on periodontal conditions in adults, measured by CPITN . Int Dent J 1987;37:169-172.

-32 Baelum V, Papapanou PN: CPITN and the epidemiology of periodontal disease. Community Dent Oral Epidemiol 1996;24:367368. 